\title{
Effect of the mixed herbal medicines extracts on menopausal symptoms: A randomized clinical trial study
}

\author{
Inessa A. Minenko ${ }^{1}$, Rumisa R. Berihanova ${ }^{2}$, Svetlana A. Shakhmatova ${ }^{3}$
}

\begin{abstract}
Background: Menopause cause many symptoms, which may impair quality of life the women. The study aims to determine the effectiveness of mixed herbal medicinal extracts on menopausal symptoms.

Method: A randomized, triple-blind, placebo-controlled clinical trial was conducted on 120 peri-menopausal women for 12 weeks. All participants took herbal extracts drops orally daily. They were randomly allocated into four groups: placebo (C), A (250 mg chamomile, $30 \mathrm{mg}$ fennel, $15 \mathrm{mg}$ saffron), B (1000 mg chamomile, $120 \mathrm{mg}$ fennel, $60 \mathrm{mg}$ saffron), and D (500 mg chamomile, $60 \mathrm{mg}$ fennel, $30 \mathrm{mg}$ saffron).They completed a demographic and MRS questionnaire at week $0,6.12$.

Result: 108 participants successfully completed the assessment. No significant differences in demographic variables were seen between the four groups. The median MRS score was significantly reduced in group B from $27.5 \pm 3$ to $7.5 \pm 5$. In group $D$, it was significantly reduced from $29 \pm 12$ to $22 \pm 9.25$ The effect size in this study was 0.92 .
\end{abstract}

Conclusion: Study showed significant improvement in menopausal symptoms especially in group $\mathrm{B}$.

Keywords: menopause, herbal medicine, alternative medicine

\section{INTRODUCTION}

Menopause disturbs all aspects of a woman's life and annually affecting 25 million women worldwide. WHO (World Health Organization) estimates that 1.2 billion women will be postmenopausal by 2030 (1). Menopause is described as the transition from the reproductive phase of a woman to the non-reproductive, it occurs in many industrial countries on average at age 51. However, in Iran, according to Rajaeefard 's study the mean age of menopause was 48.18 years (2). Hence, menopause starts between the age of 40 and 50 and is marked by the reduction of estrogen levels (3). Most of these problems can be effectively treated with HRT (hormone replacement therapy). However, HRT may cause serious risk hazards to one's health, and is therefore only recommended for temporary, limited therapy (3). The possible adverse effects of long-term HRT have lead women to seek out alternative therapies (4). Nowadays, complementary and alternative therapies to treat menopausal symptoms in place of HRTare pharmaceutical and botanical (5). Because menopause includes a variety of symptoms (such as hot flashes, night sweats, genital problems such as vaginal dryness, dysuria and urinary disorders, sexual dysfunction and lack of sexual satisfaction, dyspareunia, pain, skeletal, heart problems and cardiovascular disorders, memory problems, and mood disorders and depression) a combination of several plants with the least side effects to reduce most symptoms is often required. Yakoot and change on the effects of the herbal combination reported helpful consequences on menopausal symptoms $(6,7)$. According to the literature, many medicinal plants can be effective in improving menopausal symptoms. For example, chamomile and fennel as phytoestrogens, alleviate hot flashes, strengthen the reproductive and urinary system, and increase sexual desires. Fennel has a positive effect on osteoporosis (8-10). Chamomile is also effective in digestive system dysfunction and it can be used as a sedative $(11,12)$. Saffron is effective in relieving depression because it is a mood modifier, as well as improving heart and vascular problems and sexual dysfunction in menopausal women (13-15). The effect of these herbal extracts on menopausal symptoms was the aim of our study.

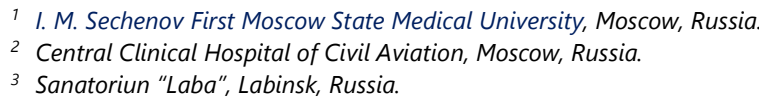

Received: 9 Feb 2019, Accepted: 21 Apr 2019

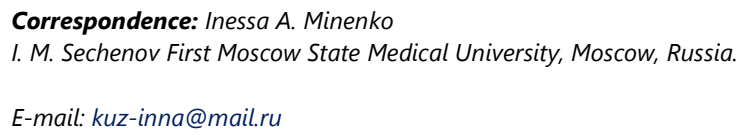

(C) 2019 by the authors; licensee Modestum Ltd., UK. This article is an open access article distributed under the terms and conditions of the Creative Commons Attribution License (http://creativecommons.org/licenses/by/4.0/). 


\section{METHODS}

1. Study Participants and Design: We conducted a randomized clinical trial and placebo controlled study at the Medical University of Mashhad, Iran. This research was approved by Ethics Committee approval of the Mashhad University. The study was triple blind and was conducting on women with menopausal symptoms. All the eligible participants were peri - menopausal women. Inclusion criteria included: cease of menstruation within 12 months of our study or presently experiencing menopausal symptoms and age range 45-65.

2. Randomization and Blinding: An independent data manager carried out randomization by using random allocation sequence. Allocation concealment was achieved through sequentially numbered, sealed envelopes. After the baseline questionnaire was completed, eligible participants were assigned to one of the four study groups by consecutively opening the envelopes as they entered the study. The probability of being allocated to the placebo group (C) and medicinal groups ( $A, B, D)$ was equal (1:1:1:1). Participants, the research staff and analysts were unaware of their assignment to the treatment or placebo.

3. Sample Size: Data from previous studies were used to calculate sample size. (16). Equal sample size for each group was anticipated at about 27 women; therefore, a total sample size of 108 participants was required, but we enrolled 120 participants considering the $10 \%$ attrition rate. For more confidence, at the beginning of the research, a pilot study was carried out and the effect size obtained was 0.92 .

4. Data collection scales: For data collection, a demographic and $\mathrm{MRS}^{1}$ questionnaire were used. Demographic data included: age, BMI, and education level of the study subject and her spouse and their occupations. The standardized MRS questionnaire is a health-related scale that collects comprehensive data. It measures three dimensions: somatic symptoms of menopause (vasomotor), psychological, and urogenital. This questionnaire has been used in many clinical studies and epidemiology research to determine the frequency and Severity of menopausal symptoms in middle-aged women and according to many studies; it has a high reliability and validity (17-19). This questionnaire has internal and external validity and reliability as established by previous studies $(20,21)$. Simbar determined the reliability by Cronbach's alpha $\left(r_{a}=0.933\right)(22)$. In this study, the reliability of the questionnaire was examined by the Cronbach's alpha $\left(r_{a}=0.9\right)$.

5. Intervention: The plant extracts and placebo agents were supplied by Exir Golesorkh Pharmaceutical Co., Ltd. The main plant extract components were fennel, chamomile, and saffron. In other similar studies, the fennel dose was $120 \mathrm{mg}$ a day, for saffron it was $60 \mathrm{mg}$ daily, and for chamomile it was $1000 \mathrm{mg}$ a day (23-25). In our study, we examined the effect of these three herbs in 3 concentrations. The high dose (group B) contained a combination of $120 \mathrm{mg}$ of fennel extract, $60 \mathrm{mg}$ of saffron extract, and $1000 \mathrm{mg}$ of chamomile extract. In medium dose (group D) was $60 \mathrm{mg}$ fennel extract, $30 \mathrm{mg}$ saffron extract, and $500 \mathrm{mg}$ chamomile extract. In low dose (group A) was $30 \mathrm{mg}$ fennel extract, $15 \mathrm{mg}$ saffron extract and $250 \mathrm{mg}$ chamomile extract and placebo (group C) (sterile $\mathrm{dH} 2 \mathrm{O}$ ). Selected women received a complete written and oral description of the study before signing an informed consent form. Next, the women were randomized in to one of four study groups. All study participants completed demographic and MRS questionnaires under the same circumstances at baseline, $6^{\text {th }}$ week, and then at $12^{\text {th }}$ week. Then for 12 weeks one group received placebo, 3 other groups received medium, low and high dose of extract 25 drops daily. Since this was a triple-blinded trial and only the pharmacist was aware of the contents of the bottle, each participant was given a bottle that was labeled with $A, B, C$, or D. At that time, the women were also requested to report if they experienced any adverse effects.

Outcome measures: Menopause symptoms

6. Statistical Analysis: Data analysis was conducted using SPSS (version 23) statistical software. The level of significance was set at $P<0.05$. Differences in group characteristics and baseline values were analyzed using the following: Kruskal-Wallis test for continuous variables with abnormal distributions, Anova for normally distributed Quantitative variables, and the Kolmogorov-Smirnov test to detect the normality of variables. To compare treatment effects on the outcome measures within and between group changes, the Wilcoxon and Friedman test were used. Also prism 6 software was used to create the graphs.

\section{RESULTS}

108 women fulfilled the eligibility criteria and successfully completed the baseline assessment with complete data for the entire 12-weeks clinical trial. Study retention was excellent (90\%). One participant in group B and one participant in

\footnotetext{
${ }^{1}$ Menopause Rating Scale
} 
Table 1: Background data

\begin{tabular}{|c|c|c|c|c|c|c|}
\hline Characteristic & groups & A & B & C & D & $\mathbf{P}$ \\
\hline \multicolumn{2}{|r|}{$\begin{array}{c}\text { Age } \\
\text { Median }\end{array}$} & 51.53 & 51.63 & 51.50 & 51.20 & 0.985 \\
\hline \multicolumn{2}{|r|}{$\begin{array}{c}\text { BMI } \\
\text { Median }\end{array}$} & 22.53 & 22.66 & 22.73 & 22.64 & 0.983 \\
\hline \multirow{3}{*}{$\begin{array}{l}\text { Woman Job } \\
\text { Number }\end{array}$} & housewife & 17 & 16 & 16 & 19 & \multirow{3}{*}{0.827} \\
\hline & Employee & 13 & 13 & 12 & 10 & \\
\hline & Worker & 0 & 1 & 2 & 1 & \\
\hline \multirow{4}{*}{$\begin{array}{l}\text { spouse Job } \\
\text { Number }\end{array}$} & Unemployed & 0 & 0 & 0 & 0 & \multirow{4}{*}{0.455} \\
\hline & employee & 26 & 20 & 24 & 23 & \\
\hline & Free job & 4 & 9 & 4 & 6 & \\
\hline & Worker & 0 & 1 & 2 & 1 & \\
\hline \multirow{3}{*}{$\begin{array}{c}\text { Woman Education } \\
\text { Number }\end{array}$} & illiterate & 1 & 4 & 4 & 3 & \multirow{3}{*}{0.846} \\
\hline & Diploma & 16 & 13 & 12 & 14 & \\
\hline & Collage education & 13 & 13 & 14 & 13 & \\
\hline \multirow{3}{*}{$\begin{array}{c}\text { Spouse Education } \\
\text { Number }\end{array}$} & illiterate & 1 & 3 & 2 & 2 & \multirow{3}{*}{0.849} \\
\hline & Diploma & 12 & 9 & 10 & 13 & \\
\hline & Collage education & 17 & 18 & 18 & 15 & \\
\hline
\end{tabular}
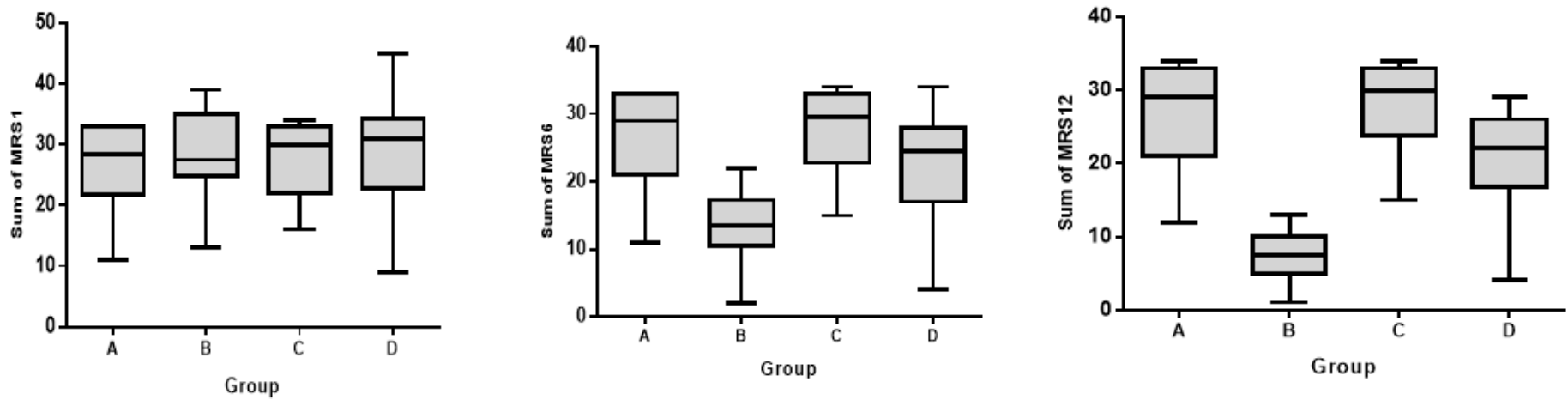

Figure 1: Comparison of the MRS scores at first, 6 th and $12^{\text {th }}$ week of treatment in 4 groups

group $D$ withdrew because of flushing and one participant in group $D$, four participants in group $A$, and five participants in group $C$ withdrew because they did not experience any change in their menopausal symptoms.

Confidence interval was $95 \%$. Test results for data normalization that were obtained by the Kolmogorov- Smirnoff indicated that age and $\mathrm{BMI}$ in all the subjects were not normal $(P=0.01,0.04)$. Mean scores of MRS questionnaire were not normal $(P<0.001)$. There were no differences between groups regarding demographic data (Table 1).

Statistically significant difference was not observed in the MRS score in the first week. However, significant differences were in the sixth $(p<0.001)$ and twelfth weeks $(P<0.001)$ (Figure 1).

We compared the MRS score in the first week with the sixth and twelfth week and sixth week with the twelfth. No statistically significant differences were seen between group $A$ and $C$, but statistically significant differences were seen between group $B(p<0.001)$ and $D(p<0.001)$ in all weeks (Figure 2$)$. 

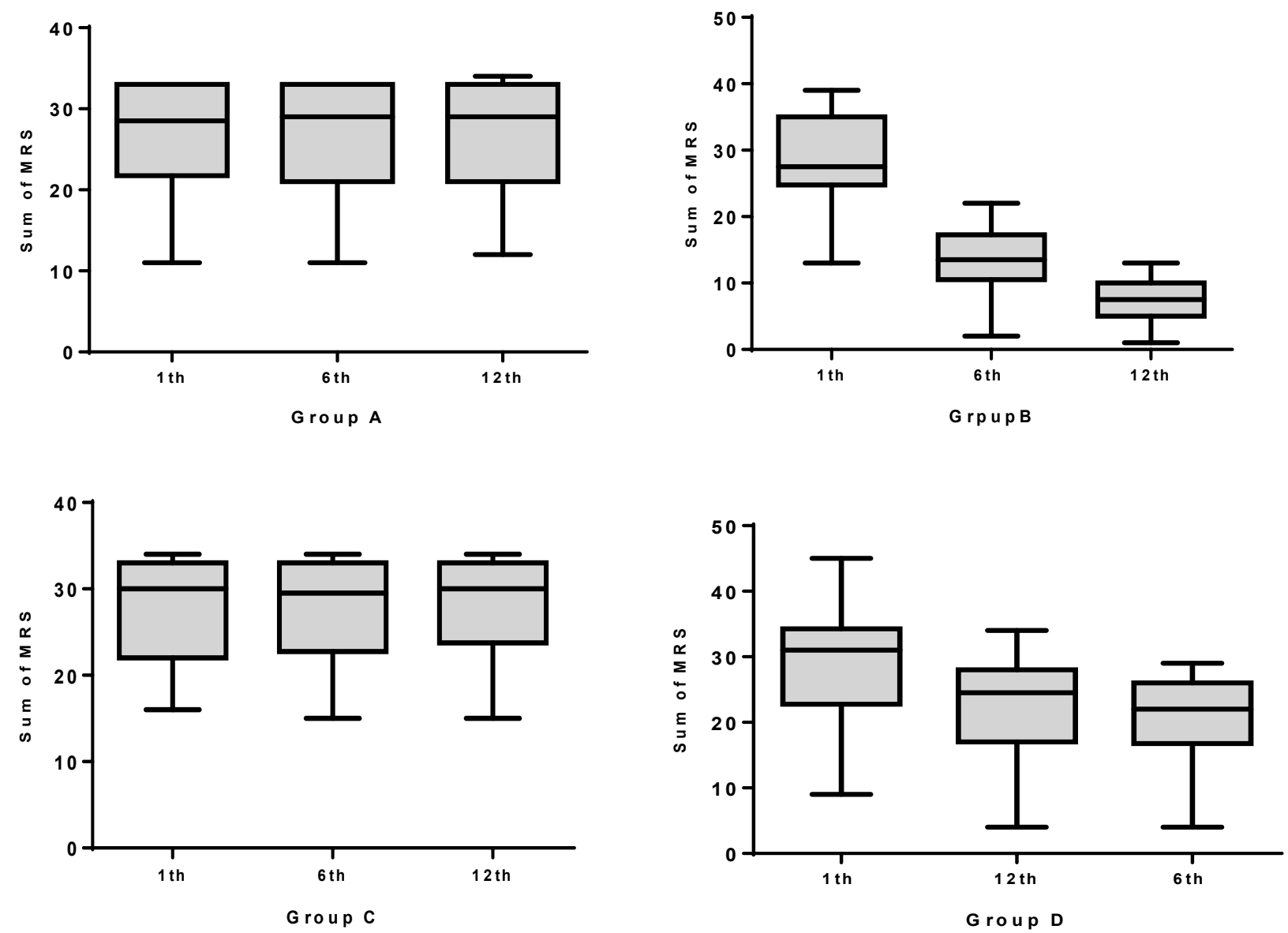

Figure 2: Comparison of the MRS scores in every group at the 1 th, 6 th and $12^{\text {th }}$ weeks

Table 2: Comparison the median and inter quarter range in MRS score at Different weeks

\begin{tabular}{|c|c|c|c|c|c|c|}
\hline \multirow{2}{*}{$\begin{array}{l}\text { Week } \\
\text { Group }\end{array}$} & \multicolumn{2}{|c|}{ MRS 1th week } & \multicolumn{2}{|c|}{ MRS 6th week } & \multicolumn{2}{|c|}{ MRS 12th week } \\
\hline & Median & IQR & Median & IQR & Median & IQR \\
\hline $\mathbf{A}$ & 28.5 & 11 & 29 & 12 & 29 & 12 \\
\hline B & 27.5 & 10 & 13.5 & 6.75 & 7.5 & 5 \\
\hline C & 30 & 18 & 5.29 & 10.25 & 30 & 9.25 \\
\hline D & 29 & 12 & 24 & 11 & 22 & 9.25 \\
\hline KOROSCAL -WALLIS & \multicolumn{2}{|c|}{ Chi-square:0.683 } & \multicolumn{2}{|c|}{ Chi-square:51.46 } & \multicolumn{2}{|c|}{ Chi-square:68.731 } \\
\hline
\end{tabular}

No significant statistical differences in the first week were observed between the groups. However, in the sixth week, there were significant differences between group $B(p<0.001)$ and all other groups. A significant statistical difference between groups $D$ and $C(p<0.01)$. In week 12 significant statistical difference was also observed between group $B$ and all other groups $(P<0.001)$. Significant statistical differences between group $D$ existed, when compared with all other groups at week $12(\mathrm{P}=0.01)$ (Table 2$)$.

\section{DISCUSSION AND CONCLUSION}

In this study, we evaluated the effects of a compound herbal medicine on menopause symptoms. This randomized, triple-blind, placebo-controlled showed that our herbal extract effectively improved various climacteric symptoms. In MRS score, groups B and D showed significant improvement within groups when compared the sixth and twelfth week with baseline. With comparing groups $A$ and $C$ in the sixth week to the twelfth and first week, their symptoms aggravated. Comparing the groups in the sixth week, group $B$ had the most improvement. In the twelfth week, there was improvement in groups B and D. However, group B showed significant improvement when compared with group D. In consistence of our study, significant decreases in all MRS scores were reported in postmenopausal women after 12 weeks of Traditional Chinese Medicine (26). Akbari reported that fenugreek and flaxseed did not influence the severity and frequency of hot 
flushes before eight weeks, but after eight weeks a decrease in severity and frequency was observed in subjects who used fenugreek (27). Our trial also was 12 weeks, but from $6^{\text {th }}$ week, significant improvement were seen. In the effectiveness of an herbal extract, statistically significant improvement was observed in the MRS-II score in both groups after two and four weeks of treatment; the improvement was significantly better in the Lady 4 group (6). Kupfersz reported a decrease only in number and intensity of hot flushes from baseline. There was also a marked alleviation of sleep disturbances and fatigue (16). Also Chang reported, KMI (the mean Kupperman Menopause Index) score was significantly reduced in the EstroG-100 treatment group when compared to that of the placebo group (7). Green reported treatment by qualified herbal practitioners was able to reduce the total scores of the GCS (Greene Climacteric Scale) (28). But, Plotnikoff reported treatment failure in Japanese herbal medicine. TU-025 did not demonstrate efficacy beyond the placebo for reducing the severity and frequency of hot flash symptoms, climacteric symptoms, or disrupted sleep symptoms in post-menopausal American women (29). Although the mechanism underlying menopause symptoms has not been fully clarified, the results of various basic and clinical studies have indicated that dramatic changes in the hormonal environment, especially the sharp decline of estrogen, during menopause play key role. We though most of these herbal medicines, alleviate the menopausal symptoms because of phytoestrogenic effects. In our study we examined two phytoestrogen herbal medicine plus Saffron that had synergism effect on menopausal symptoms. The strengths of the study are that it was a randomized controlled trial of a complex medical intervention of quality complementary and alternative medicine. The length of the trial was adequate to measure changing. No adverse events were observed or reported by participants who received the herbal extracts. The study limitation was the somewhat small size. A larger population is needed to confirm the results and to increase the statistical power of the study.

The 12-week treatment with the herbal compound showed a statistically significant improvement in the various menopausal symptoms in group B.

\section{ACKNOWLEDGEMENTS}

This study was supported by a grant from the Russian Foundation for Basic Research (RFHR), project No. 17-0100434-a.

\section{REFERENCES}

1. Stephenson KNP, Kurdowska AK. The effects of compounded bioidentical transdermal hormone therapy on hemostatic, inflammatory, immune factors; cardiovascular biomarkers; quality-of-life measures; and health outcomes in perimenopausal and postmenopausal women. International journal of pharmaceutical compounding. 2012;17(1):74-85.

2. Rajaeefard A, Mohammad-Beigi A, Mohammad-Salehi N. Estimation of natural age of menopause in Iranian women: a meta-analysis study. Koomesh. 2011;13(1):1-7.

3. Aidelsburger P, Schauer S, Grabein K, Wasem J. Alternative methods for the treatment of post-menopausal troubles. GMS health technology assessment. 2012;8:353-368.

4. Kim M-S, Lim H-J, Yang HJ, Lee MS, Shin B-C, Ernst E. Ginseng for managing menopause symptoms: a systematic review of randomized clinical trials. J Ginseng Res. 2013;37(1):30-6. https://doi.org/10.5142/jgr.2013.37.30 PMid:23717154 PMCid:PMC3659624

5. Ernst E, Pittler MH, Wider B, Boddy K. Oxford handbook of complementary medicine: OUP Oxford; 2008. https://doi.org/10.1093/med/9780199206773.001.0001

6. Yakoot M, Salem A, Omar A-M. Effectiveness of a herbal formula in women with menopausal syndrome. Forschende Komplementärmedizin/Research in Complementary Medicine. 2011;18(5):264-8. https://doi.org/10.1159/000333430 PMid:22105039

7. Chang A, Kwak BY, Yi K, Kim JS. The Effect of Herbal Extract (EstroG-100) on Pre-, Peri-and Post-Menopausal Women: A Randomized Double-blind, Placebo-controlled Study. Phytotherapy research. 2012;26(4):510-6. https://doi.org/10.1002/ptr.3597 PMid:21887807

8. Sara Pourabbas M. Study of the the anxiolytic effects of fennel and possible roles of bothGABAergic system and estrogen receptors in these effects in adult female rat,. Physiology and Pharmacology. Spring [Article in Persian. 2011;15(1):134-43.

9. Kim T-H KH-J, Lee S-H, Kim S-Y. Potent inhibitory effect of Foeniculum vulgare Miller extract on osteoclast differentiation and ovariectomy-induced bone loss. International journal of molecular medicine. 2012;29(6):1053. 
10. Malini VG, Megala N, Anusya S, Devi K, Elango V. Effect of Foeniculum vulgare Mill. Seed extract on the genital organs ofmale and female rats. indian J physiol pharmacol. 1985;29(1):21-6.

11. Barene IDI, Zvirgzdina L, Iriste V. The complex technology on products of German chamomile. Medicina. 2003;39(2):127-31.

12. Zeggwagh NA, Eddouks M. Vascular Effects of Aqueous Extract of Chamaemelum nobile: In Vitro Pharmacological Studies in Rats. Clinical and Experimental Hypertension. 2013;35(3):200-6. https://doi.org/10.3109/10641963.2012.712179 PMid:22866985

13. Emamghoreishi GFY. The Effect of Subchronic Administration of the Aqueous and Hydro-alcoholic Extracts of Crocus sativus from Estahbanat, Fars Province, on Mice (in persion). Armaghane-danesh, Yasuj University of Original Article Medical Sciences Journal. 2011;2(3):115-123.

14. Kashani L RF, Saroukhani S, Sohrabi H, Modabbernia A, Nasehi AA, et al. Saffron for treatment of fluoxetineinduced sexual dysfunction in women: randomized double-blind placebo-controlled study. Human Psychopharmacology: Clinical and Experimental. 2013;28(1):54-60. https://doi.org/10.1002/hup.2282 PMid:23280545

15. Rajput MS SS, Mathur V, Agrawal P. Herbal antidepressants international JPharmaceutical Frontier Resl. 2011;1(1):159-69.

16. Kupfersztain C, Rotem C, Fagot R, Kaplan B. The immediate effect of natural plant extract, Angelica sinensis and Matricaria chamomilla (Climex) for the treatment of hot flushes during menopause. A preliminary report. Clinical and experimental obstetrics \& gynecology. 2002;30(4):203-6.

17. Heinemann LA, Potthoff $P$, Schneider HP. International versions of the menopause rating scale (MRS). Health and quality of life outcomes. 2003;1(1):28. https://doi.org/10.1186/1477-7525-1-28

18. Schneider $H$, Heinemann $L$, Thiele K. The Menopause Rating Scale (MRS): cultural and linguistic translation into English. Life and Medical Science Online. 2002;3:65-73.

19. Heinemann K, Ruebig A, Potthoff $P$, Schneider HP, Strelow F, Heinemann LA. The Menopause Rating Scale (MRS) scale: a methodological review. Health and Quality of life Outcomes. 2004;2(1):45-59. https://doi.org/10.1186/1477-7525-2-45

20. Al Msae. The frequency and severity of menopausal symptoms and its relationship with personal factors the young women before and after menopause in Ahvaz. IJOGl. 2013;16:7-15.

21. Jalili LHN, DPA, Najar EAMS. T. The relationship between physical activity and intensity. Menopausal symptoms in postmenopausal women in Ahvaz. IJOGI May 2014;17(98):15-23.

22. S. Nazarpour MS FRT. Effects of the severity of menopausal symptoms on sexual function in postmenopausal women. JQUMS, 2015;19:54-63.

23. Agha-Hosseini MKL, Aleyaseen A, Ghoreishi A, Rahmanpour H, Zarrinara A. Crocus sativus L.(saffron) in the treatment of premenstrual syndrome: a double-blind, randomised and placebo-controlled trial. BJOG: An International Journal of Obstetrics \& Gynaecology. 2008;115(4):515-9. https://doi.org/10.1111/j.14710528.2007.01652.x PMid:18271889

24. Amsterdam JD L Slea. A Randomized, double blind, placebo-controlled trial of oral Matricara recutita (chamomile) extract therapy for generalized anxiety disorder. J Clin Psychopharmacol. 2009;29(4):378-82. https://doi.org/10.1097/JCP.0b013e3181ac935c PMid:19593179 PMCid:PMC3600416

25. Omidvar S ES, Baradaran M, Basirat Z. Effect of fennel on pain intensity in dysmenorrhoea: A placebo-controlled $\begin{array}{llll}\text { trial. } & \text { AYU. } 2012 \quad \text { Apr;33(2):311-3. https://doi.org/10.4103/0974-8520.105259 PMid:23559811 }\end{array}$ PMCid:PMC3611645

26. Nedeljkovic M, Tian L, Ji P, Déglon-Fischer A, Stute P, Ocon E, et al. Effects of acupuncture and Chinese herbal medicine (Zhi Mu 14) on hot flushes and quality of life in postmenopausal women: results of a four-arm randomized controlled pilot trial. Menopause. 2014;21(1):15-24. https://doi.org/10.1097/GME.0b013e31829374e8 PMid:23676632

27. Akbari Torkestani N, Attarha M, Heidari T, Narenji F. The Effect of Fenugreek and Flaxseed on Menopausal Hot Flash. Complementary Medicine Journal of faculty of Nursing \& Midwifery. 2011;1(1):68-74. 
28. Green J DA, Ingram J, Hawkey S and Greenwood R. Treatment of menopausal symptoms by qualified herbal practitioners: a prospective, randomized controlled trial. Family Practice Advance Access 14 August 2007;24:46874. https://doi.org/10.1093/fampra/cmm048 PMid:17698978

29. Plotnikoff GA, Watanabe K, Torkelson C, La Valleur J, Radosevich DM. The TU-025 Keishibukuryogan for Hot Flash Management in Postmenopausal Women: Results and Lessons for Future Research. Menopause (New York, NY). 2011;18(8):886. https://doi.org/10.1097/gme.0b013e31821643d9 PMid:21738077 PMCid:PMC3181094

$$
\diamond \diamond \diamond \diamond \diamond \diamond \diamond
$$

http://www.ejgm.co.uk 